\title{
SEQUESTRO DA SUBJETIVIDADE: \\ REVISITAR O CONCEITO E APREENDER O REAL ${ }^{1}$
}

\begin{abstract}
Deise Ferraz ${ }^{2}$
http://dx.doi.org/10.1590/1413-2311.238.89885

\section{RESUMO}

O conceito sequestro da subjetividade, desenvolvido por Faria e Meneghetti (2007), tem sido acionado para explicar fenômenos intra-organizacionais, sobretudo quando os objetos de estudo são as relações de trabalho. Muitas reflexões já resultaram desses estudos, porém, quando analisado o conceito em si observo que ele expressa a aparência do fenômeno, pois na essência trata-se da produção de uma subjetividade correspondente ao modo de produção metabólico do capital e de sua apropriação privada. Assim, o objetivo deste ensaio é discutir o conceito de "sequestro da subjetividade" e a realidade que ele se propõe explicar.
\end{abstract}

Palavras-Chave: Sequestro da Subjetividade. Alienação-Estranhamento. Objetividadesubjetividade. Luta de classes. Captura da Subjetividade.

SUBJECTIVITY KIDNAPPING:

REVISITING THE CONCEPT AND APPREHENDING THE REAL

\footnotetext{
ABSTRACT

${ }^{1}$ Recebido em 28/01/2019; aprovado em 24/02/2019,

${ }^{2}$ Universidade Federal de Minas Gerais - Faculdade de Ciências Econômicas da Universidade Federal de Minas Gerais e Núcleo de Estudos Críticos Trabalho e Marxologia; Belo Horizonte - MG (Brasil) deiseluizaferraz@gmail.com
} 
The concept of the kidnapping of subjectivity, developed by Faria and Meneghetti (2007), has been used to explain intra-organizational phenomena, especially when the objects of study are labor relations. Many reflections have already resulted from these studies, however, when we analyze the concept itself, we see that it expresses the appearance of the phenomenon, whereas in essence it is the production of a subjectivity corresponding to the metabolic mode of production of capital and its private appropriation. Thus, the goal of this essay is to discuss the concept of "subjectivity kidnapping" and the reality it proposes to explain.

Keyword: Subjectivity kidnapping. Alienation. Objectivity-subjectivity. Class struggle.

Subjectivity capture

\section{SECUESTRO DE LA SUBJETIVIDAD: REVISITAR EL CONCEPTO Y APREHENDER LO REAL}

\section{RESUMEN}

El concepto secuestro de la subjetividad, desarrollado por Faria y Meneghetti (2007), ha sido accionado para explicar fenómenos intra-organizacionales, sobre todo cuando los objetos de estudio son las relaciones de trabajo. Muchas reflexiones ya resultaron de esos estudios, pero cuando analizamos el concepto en sí observamos que él expresa la apariencia del fenómeno, pues en la esencia se trata de la producción de una subjetividad correspondiente al modo de producción metabólico del capital y de su apropiación privada. De este modo, el objetivo de este ensayo es discutir el concepto "secuestro de la subjetividad" y la realidad que él se propone explicar.

Palabras clave: Secuestro de la subjetividad. Alienación., Objetividad-subjetividad. Lucha de clases. Captura de la Subjetividad.

\section{INTRODUÇÃO}

O conceito sequestro da subjetividade, desenvolvido por Faria e Meneghetti (2007), tem sido acionado para explicar fenômenos denominados intra-organizacionais, sobretudo quando os objetos de estudo são as relações de trabalho. Muitas reflexões já resultaram de 
estudos que assumiram que:

O sequestro da subjetividade por parte da organização consiste no fato desta apropriar-se, planejadamente, através de programas na área de gestão de pessoas, e de forma sub-reptícia, furtiva, às ocultas, da concepção de realidade que integra o domínio das atividades psíquicas, emocionais e afetivas dos sujeitos individuais ou coletivos que a compõem (trabalhadores, empregados). Estas atividades formam a base da percepção e da representação que permite aos sujeitos interpretar o concreto pela via do pensamento e tomar atitudes (agir). O sequestro da percepção e da elaboração subjetiva priva os sujeitos de sua liberdade de se apropriar da realidade e de elaborar, organizar e sistematizar seu próprio saber, ficando à mercê dos saberes e valores produzidos e alimentados pela organização sequestradora (FARIA; MENEGHETTI, 2007, p.50).

Porém, quando analisado o conceito em si, observo que ele expressa a aparência do fenômeno, pois na essência trata-se da produção de uma subjetividade correspondente ao modo de produção metabólico do capital e de sua apropriação privada, algo não demonstrado no texto dos autores aqui analisado. Deste modo, o objetivo deste ensaio é discutir o conceito "sequestro da subjetividade" e a realidade que ele se propõe explicar a partir da discussão de subjetividade-objetividade realizada por Marx (2006, 2011, 2013). Apenas no estabelecimento dessa relação será possível compreender a essência da produção e da apropriação da subjetividade sob o comando do capital. Colocar Marx como interlocutor não fere a perspectiva de Faria e Meneghetti (2007), pois eles assumem a crítica ao capital, além de Faria ser a grande referência marxista em nosso campo de estudo, responsável pela formação de muitos pesquisadores no marxismo, fonte acadêmica que inspirou outros tantos, incluindo a autora.

Destaco: o objetivo não é fácil! Como duvidar de um conceito que possui envergadura teórica? Que expressa aquilo que é vivido, de forma imediata, pelas trabalhadoras ${ }^{3}$ em suas relações laborais? Ademais, há um elemento que muitas vezes pode dificultar a realização da crítica, qual seja: o afeto. No processo de produção e minha subjetividade, as relações

\footnotetext{
${ }^{3}$ Embora reconheça que a alteração linguística de flexão de gênero não possui determinância alguma na alteração concreta das condições que produzem a opressão das mulheres, opto por referir-me ao trabalhador e à trabalhadora pela palavra trabalhadora (ou em sua variação de número: trabalhadoras), exceto nas citações diretas. Se a alteração linguística não tem força suficiente para alterar as condições de opressão, pelo menos traz o desconforto da leitura, lembrando que vivemos em uma sociedade cujas relações são de exploração, mas também de opressão. Portanto, sempre que lerem trabalhadora(s), entendam trabalhadora(s) e trabalhador(es).
} 
estabelecidas com Faria e Meneghetti (2007) são de afetividade positiva. Elaborar o questionamento a esses autores, portanto, demanda aceitar outra colocação de Faria: a crítica é uma forma de amor. Assumido esse desafio amoroso analiso o conceito em tela, tendo como expectativa contribuir para o avanço da apreensão do real pelo pensamento. Para tanto, no caso dessa investigação, assumo como objeto a ser analisado as reflexões acerca das relações de controle do trabalho sob o comando do capital descritas no texto ' $O$ sequestro da Subjetividade' (publicado em 2007 no livro 'Análise Crítica das Teorias e Práticas Organizacionais'); e no subitem 'O controle e o Sequestro da Subjetividade' presente no livro 'Poder Controle e Gestão: Uma Crítica das Organizações Produtivas' de autoria de Faria (2017). Esse ensaio está estruturado de modo que no próximo item apresento a concepção de subjetividade em Marx e o desenvolvimento particular da subjetividade no sociometabolismo do capital. No item subsequente, discuto o texto de Faria e Meneghetti (2007) propriamente dito e, para finalizar, apresento uma breve discussão sobre a necessidade de superar a aparência do real expressa no conceito sequestro da subjetividade para compreender que a única forma de libertação da trabalhadora é pela superação da auto-alienação do trabalho, pois no sociometabolismo do capital não há liberdade humana.

\section{SUBJETIVIDADE $\mathrm{E}$ A PRODUÇÃO DO INDIVÍDUO RACIONALMENTE EGOÍSTA}

A discussão sobre a subjetividade e a produção histórica de um indivíduo racionalmente egoísta é muito cara para a filosofia marxiana. Nela, a subjetividade só pode ser compreendida em sua relação de reciprocidade dialética com a objetividade, portanto, no estudo das relações sociais é imprescindível a não cisão do par objetividade-subjetividade. Não se trata, assim, de mero corte analítico, mas de uma necessidade interna do concreto que se impõe no processo de construção do concreto pensado. Ainda que de forma sumária, alguns pontos essenciais dessa discussão serão apresentados, em dois subitens específicos. No primeiro, trarei a discussão sobre o referido par e, no segundo, a construção histórica de uma individualidade particular: o indivíduo racionalmente egoísta. Por que tratar esses dois temas? Porque falar em processo de individuação na generidade humana é demonstrar o processo de complexificação das relações sociais que produziu e produz as possibilidades de conteúdos singulares para uma forma histórica da subjetividade: a racionalidade egoísta, produto de relações concretas de dependência entre indivíduos mutuamente indiferentes. 


\subsection{O PAR OBJETIVIDADE-SUBJETIVIDADE E A CONSTITUIÇÃO DA INDIVIDUALIDADE}

Marx não elabora nenhum texto específico em que trata da relação objetividadesubjetividade, mas essa relação marca sua obra devido à concepção ontológica adotada por ele - sobretudo os escritos elaborados após o texto "Crítica da Filosofia do Direito de Hegel" (1843). Porém, alguns textos são mais oportunos para realizar tal discussão, quais sejam: "Sobre a Questão Judaica" (1843), "Manuscritos Econômicos-Filosófico" (1844), “A Ideologia Alemã" (1845-1846) e "Grundrisse" (1857-1858). Quem se debruça nos estudos desses livros, observa as ligações internas no pensamento do autor, o que permite afirmar a não existência de diferentes $\mathrm{Marx}^{4}$, mas sim de um intelectual cujo intelecto está em desenvolvimento.

Costa (2006, p. 1-2) ao analisar os Manuscritos afirma:

Da análise dos economistas clássicos à discussão com Hegel, todas as formulações se atêm a esta descoberta: o homem como produtor de si mesmo através da atividade sensível. Atividade que envolve objetividade e subjetividade, entrelaçadas na produção material, que faz da vida do homem uma forma radicalmente nova de existência, distinta e mais complexa do que todo movimento da natureza.

Para Marx, o trabalho (protoforma da atividade humana em geral) é um processo em que ocorre a interiorização do objetivo (do existente fora do sujeito - do mundo sensível exterior) pelo humano sensível (espécie animal dotada das necessárias condições - órgãos do sentido e cognição - produzindo uma subjetividade humana) e uma externalização dessa subjetividade em uma nova objetividade. Essa nova objetividade, produto do trabalho, é "o trabalho que se fixou no objeto" (MARX, [1844] $]^{5}$ 2006, p. 80). Eis o processo ativo de produção objetiva que satisfaz as carências humanas - sejam elas do estômago ou da fantasia, como afirmou Marx n'O Capital.

Ainda cabe destacar que, nesse processo de subjetivação da objetividade e objetivação da subjetividade:

1) A objetividade como primazia ontológica da subjetividade - destaca Bicalho (2012, p.

133) que "A objetividade é ontologicamente pressuposta para qualquer evento

\footnotetext{
${ }^{4}$ Sobre a polêmica do Jovem e Velho Marx exposta por Althusser, ver a discussão realizada por Mészáros (2006).

${ }^{5}$ Embora não seja regra da ABNT, informo os anos da escrita ou publicação dos textos de Marx, antes de informar o ano de publicação do livro utilizado para a produção desse texto.
} 
subjetivo. Não é possível haver pensamento sem a materialidade do ser".

2) Toda objetividade, produto de uma ação humana, é uma objetividade engendrada pelo e no processo de externalização da subjetividade sobre objetividades postas, sendo produto colocado para novas subjetivações-objetivações.

3) Para compreender a constituição da subjetividade necessita-se, como dito, da análise do par objetividade-subjetividade, porém, não nos termos da problemática de ser ou o indivíduo ou a sociedade os agentes determinantes do processo. Isso porque, para Marx ([1857-1858] 2011, p. 205), "a sociedade não consiste de indivíduos, mas expressa a soma de vínculos, relações em que se encontram esses indivíduos uns com os outros". Desta forma, não há como falar em indivíduo fora da sociedade, tampouco de discutir a subjetividade defendendo ora a influência determinante do indivíduo na constituição da sociedade, ora a sociedade determinando a formação da subjetividade individual. Sendo a sociedade a expressão das relações que os indivíduos estabelecem uns com os outros, a constituição do indivíduo e da sociedade se opera no mesmo ato. Ato, ou o que é o mesmo, atividade, que contém o momento da subjetivação da objetividade e da objetivação da subjetividade - não esquecendo que as condições em que essas relações se desenvolvem são resultantes de relações anteriores e que na sociabilidade do capital a conexão entre os indivíduos está transformada em um poder coisificado.

4) Reforçando o argumento anterior, se a objetivação do objeto-subjetivado põe uma nova objetividade como subjetividade-objetivada, alterando assim a própria objetividade, a relação de reciprocidade dialética está estabelecida. A objetividade humana, da qual a subjetividade é um aspecto de um mesmo fenômeno, altera-se no processo de interiorização da exterioridade e externalização da interioridade. Porém nesse processo de subjetivação da objetividade e objetivação da subjetividade, em determinadas condições históricas, como destaca Marx ([1844] 2006), o resultado das objetivações humanas não é subjetivado como tal. Eis aqui o fenômeno do estranhamento. $\mathrm{O}$ estranhamento é um aspecto determinante para que a apropriação do resultado do trabalho (protoforma de qualquer atividade) ocorra enquanto apropriação privada.

Como coloca Costa (2006), em Marx (MARX, [1844] 2006) a descoberta da humanidade como autoprodutora de si nesse duplo aspecto do movimento objetivaçãosubjetivação engendrado na produção material necessita da apropriação material e ideal do objeto a ser trabalho e dos meios de trabalho. Apropria-se materialmente quando o humano 
toma para si os elementos do processo de trabalho, idealmente quando descobre - e aqui o desenvolvimento da ciência é um desdobramento necessário daquela carência - as qualidades do objeto a ser trabalhado e as formas de melhor manipular essas qualidades para alcançar o objetivo previamente posto. Porém, essa apropriação, de modo algum é, a priori, uma propriedade privada. Falar em propriedade privada é adentrar na discussão sobre o processo de produção em geral (universal) na sua particularidade capitalista.

Marx ([1857-1858] 2011), em uma crítica aos economistas políticos que defendem a propriedade privada e a sua proteção pelos aparatos legais ou policiais, como condição para a produção, afirma que essa tese é tautológica. O autor demonstra que a produção em geral universal - é uma apropriação. “Toda produção é apropriação da natureza [da objetividade] pelo indivíduo no interior de e mediada por uma determinada forma de sociedade [...] toda forma de produção forja suas próprias relações jurídicas, forma de governo, etc. A insipiência e o desentendimento consistem precisamente em relacionar casualmente o que é organicamente conectado" (MARX, [1857-1858] 2011, p. 43) em tornar uma forma particular (a propriedade privada) em condição universal.

Marx ([1857-1858] 2011, p. 41) menciona, ainda, que todo processo de produção, produz o objeto a ser consumido e também seu consumidor: "Por isso, quando se fala de produção, sempre se está falando de produção em um determinado estágio de desenvolvimento social - da produção de indivíduos sociais" (MARX, [1857-1858] 2011, p. 41).

Para compreender a produção particular de indivíduos sociais resultante do sociometabolismo do capital, é preciso realizar uma digressão e recorrer ao entendimento das categorias generidade e singularidade, categorias que possibilitam discutir o processo de constituição do indivíduo (em sua expressão objetiva-subjetiva). Realizada essa tarefa, avanço rumo à compreensão do indivíduo racionalmente egoísta.

\subsection{GENERIDADE, SINGULARIDADE E A PARTICULARIDADE DO INDIVÍDUO RACIONALMENTE EGOÍSTA}

Antes de qualquer coisa, o ser humano é um ser animal, pertencente a um gênero, porém um gênero não mais mudo: o gênero humano. Trago abaixo a citação de Vaisman (2009, p. 451-452) que sucintamente apresenta as contribuições de Lukács sobre o problema da constituição da individualidade.

Lukács identifica o lugar genético dessa concepção, isto é, da 
superação do gênero mudo natural e o advento do gênero propriamente humano, precisamente na práxis individual que constitui o modo por meio do qual se processa a "adaptação ativa" e a partir da qual se dá, de modo contraditório e desigual, a constituição processual do ser social, nos seus dois âmbitos, ou seja, o âmbito do indivíduo e o do gênero. Em outros termos, “[...] a base ontológica do salto [do gênero mudo para o gênero não-mais-mudo - E. V.] foi a transformação da adaptação passiva do organismo ao ambiente em uma adaptação ativa, com o que a sociabilidade surge como nova maneira de generidade" (LUKÁCS 1984, p. 43). Nesse contexto, a individualidade não é entendida por Lukács como um dado humano originário, mas uma categoria que se constitui também historicamente, na base de uma "determinação recíproca" com a generidade, mas não só. Trata-se de um processo extremamente lento, inclusive, das próprias relações sociais, para que o problema da individualidade possa aparecer não só como um problema real, mas também universal.

Ou seja, o ser social se expressa na constituição simultânea, recíproca e desigual da generidade humana e de uma singularidade própria, onde o indivíduo (unidade singular) que compõe esse gênero não é somente um exemplar que compreende a expressão total de seu gênero, ainda que assim também o seja. A unidade singular do gênero humano (o indivíduo) também é uma unidade particularmente histórica (a individualidade).

Lukács (2010, p. 95) destaca que:

A individualidade como sistema próprio, socialmente determinado, de reagir às alternativas que a vida apresenta (a vida cotidiana), caracteriza hoje praticamente todos os seres humanos da sociedade e é, em termos ontológicos objetivos, um produto do desenvolvimento milenar da sociedade para uma sociabilidade tendencialmente omnilateral, é óbvio que também no processo de reprodução dos exemplares singulares do gênero.

O processo de constituição da individualidade, como não poderia deixar de ser, engendra-se e é engendrado no e pelo processo de constituição social (pontos 3 e 4 discutidos anteriormente). À compreensão desse processo de individuação é imprescindível à análise do par objetividade-subjetividade, posto que há correspondência, ainda que perpassadas por 
inúmeras mediações, entre a objetividade da vida e a subjetividade do viver. Ou como menciona Marx "é claro que a efetiva riqueza espiritual do indivíduo depende inteiramente de suas relações reais" (MARX, [1845-1846] 2007 p. 41). Sob as relações sociais comandadas pelo capital, as condições objetivas postas produzem o indivíduo racionalmente egoísta como produto social e não como essencialidade humana.

A individualidade moderna expressa-se num modo particular de ser indivíduo: o indivíduo racionalmente egoísta. Marx, ao demonstrar o desenvolvimento do modo sociometabólico do capital - categorias: mercadoria (valor de uso, valor, valor de troca), produção, circulação simples e ampliada, divisão social do trabalho, circulação da mercadoria, propriedade privada, dinheiro - destaca que a sociedade mercantil (re)produz o ser social como um conjunto de relações de dependência entre sujeitos mutuamente indiferentes. Cabe a transcrição de um trecho do Grundrisse ([1857-1858] 2011), onde o autor expõe a relação de dependência entre os indivíduos, bem como a mútua indiferença entre os indivíduos nas relações sociais decorrentes da preponderância da produção de valores de troca aos valores de uso numa sociedade em que o poder social é um poder posto nas coisas.

A dissolução de todos os produtos e atividades em valores de troca pressupõe a dissolução de todas as relações fixas (históricas) de dependência pessoal na produção, bem como a dependência multilateral dos produtores entre si. A produção de todo indivíduo singular é dependente da produção de todos os outros; bem como a transformação de seu produto em meios de vida para si próprio tornase dependente do consumo de todos os outros. [...] o próprio interesse privado já é um interesse socialmente determinado, e que só pode ser alcançado dentro das condições postas pela sociedade e com os meios por ela proporcionados; logo, está vinculado à reprodução de tais condições e meios. É o interesse das pessoas privadas; mas seu conteúdo, assim como a forma e os meios de sua efetivação, está dado por condições sociais independentes de todos. [...] O caráter social da atividade, assim como a forma social do produto e a participação do indivíduo na produção, aparece aqui diante dos indivíduos como algo estranho, como coisa; não como sua conduta recíproca, mas como sua subordinação a relações que existem independentemente deles e que nascem do entrechoque de indivíduos indiferentes entre si (MARX, [1863] 2013, p. 104-105). 
Tal indiferença sustenta-se na necessidade do trabalho abstrato enquanto substância do valor e de sua expressão, o valor de troca. Logo, em uma sociedade em que o processo de produção é determinado pelas necessidades da valorização do valor, o trabalho necessário é um trabalho indiferenciado, desprovido da personalidade da produtora (trabalhadora). $\mathrm{O}$ processo de valorização do valor, portanto, carece de um trabalho indiferenciado, não necessita do indivíduo-produtor, mas da mercadoria força de trabalho, isto é, das qualidades objetivas e subjetivas de um indivíduo que são necessárias a realização da produção subsumida ao capital. Essa mercadoria, porém, somente pode ser consumida por meio da efetivação do trabalho, por meio do indivíduo-produtor em atividade - em sua prática de trabalho. Na perspectiva do valor, se para o comprador da mercadoria força de trabalho é indiferente que essa seja produzida e vendida pelo indivíduo B ou Z, para a trabalhadora, também é indiferente quem compra a mercadoria que ela leva ao mercado, assim como também é a ele indiferente com quais outras trabalhadoras ela estará em concorrência e em cooperação no processo de trabalho sob o capital.

A dependência recíproca e multilateral dos indivíduos mutuamente indiferentes forma sua conexão social. Essa conexão social é expressa no valor de troca, e somente nele a atividade própria ou o produto de cada indivíduo devêm uma atividade ou produto para si; o indivíduo tem que produzir um produto universal - o valor de troca, ou este último por si isolado, individualizado, dinheiro. [...] seu poder social, assim como seu nexo com a sociedade, [o indivíduo] traz consigo no bolso (MARX, [1863] 2013, p. 105).

Assim, o "indivíduo recolhido ao seu interesse privado e ao seu capricho privado e separado da comunidade" (MARX, 2010, p. 50) é o humano egoísta, o humano como membro da sociedade burguesa, ou seja, não se trata de uma essência natural do ser humano.

Agora, afirmar que as condições históricas sociometabólicas do capital colocam os indivíduos em relações mutuamente indiferentes não é o mesmo que subtrair das relações humanas as expressões - também históricas - de suas subjetividades conhecidas como sentimentos, emoções, etc. Tampouco, afirmar que a dependência recíproca significa extrair do indivíduo sua capacidade de decisão sobre o seu devir - devir individual, sobre a constituição de sua personalidade -, condicionado sob o comando do capital. Os indivíduos, ainda que constituindo-se num processo de relações sociais estranhadas, na imediaticidade de suas vidas, subjetivam a objetividade (interiorização) e "decidem" sobre o que objetivam (externalização), isto é, escolhem entre as múltiplas alternativas objetivas postas socialmente 
para si. São as decisões alternativas tomadas ao longo da vida e os nexos causais delas decorrentes que constituem o que conhecemos, dito de forma sumária, como a personalidade dos indivíduos ${ }^{6}$. Quanto mais desenvolvida uma sociedade no sentido social tanto mais variadas decisões ela exige de cada um de seus membros, em todos os domínios da vida, de tal modo que, objetivamente, domínios próximos entre si podem, frequentemente, mostrar grandes diferenças no tipo de reações exigidas; pensemos no comércio e na Bolsa, no comportamento de crianças em casa e na escola etc. etc. etc. Esta multiplicidade, aparentemente quase infinita, de decisões alternativas com que o membro singular é constantemente induzido ou até mesmo obrigado a tomar pela diferenciação interna da sociedade, é o fundamento social daquilo que costumamos designar, de modo geral, como formação dos seres humanos para a individualidade.

[...] Essa grande multiplicidade de reações, muitas vezes às mesmas novas tarefas postas pelo movimento social [...] não significa, porém, que o impulso dominante desse desenvolvimento sempre tivesse sido produzido por iniciativas individuais. Ao contrário, a história mostra que tanto a crescente diferenciação dos problemas socialmente solúveis quanto sua maneira, seu conteúdo, sua forma, etc. em última análise são sempre postos na ordem do dia pelo desenvolvimento da sociedade como um todo (LUKÁCS, 2010, p. 91-92).

Lukács (2010, p. 96) afirma, ao descrever que esse reagir (adaptação ativa) àobjetividade posta e subjetivada apenas na imediaticidade são decisões singulares, que:

Em sentido abstratamente geral é correto que, tanto as tarefas socialmente relevantes só possam ser convertidas em ser por decisões alternativas dos indivíduos, quanto que nenhuma decisão alternativa pessoal possa ocorrer sem ser socialmente determinada em seus traços decisivos. Ao mesmo tempo, porém, qualquer observação imparcial de tais complexos mostra que sua relevância costuma se fazer valer nos dois polos (sociedade em seu conjunto e o homem singular) de maneira extremamente diferente.

Porém, vale destacar, assim como faz Vaisman (2009, p. 455), que a determinância social dos traços decisivos de cada reagir não é mero reflexo passivo, mas é algo que se forma no "interior das complexas vivências das 'decisões alternativas"'. Assim, a

\footnotetext{
${ }^{6}$ Para compreender melhor essa discussão, ver as considerações de Lukács (2013) sobre causalidades, espelhamento e teleologia. Importante não compreender personalidade como as abordagens mais comuns da psicologia, onde o conceito expressa algo estanque.
} 
(re)produção, com maior ou menor resistência individual, dos laços sociais como um conjunto de relações de dependência entre sujeitos mutuamente indiferentes e racionalmente egoísta não é a expressão de uma essência humana colocada à unidade da espécie humana de forma apriorística, mas uma produção histórica no desenvolvimento do gênero e no processo de individualidade engendrados pelas mediações de segunda ordem, para recorrer a Mészáros (2006). Processo no qual os momentos objetividade-subjetividade se efetuam, não existindo assim uma subjetividade isolada da produção objetiva. Não existe, portanto, uma subjetividade que possa ser sequestrada nos termos postos por Faria e Meneghetti (2007). Bem, parece ainda ser cedo para fazer essa afirmação. Pois, mesmo depois dessas digressões teóricas, ainda é difícil duvidar do que o conceito sequestro da subjetividade expressa, afinal, o expresso corresponde com o que é vivido de forma imediata pelos seres humanos em suas relações laborais. Mas a dificuldade ainda persiste porque não expus o rastreamento de seu nexo interno. As ponderações até aqui realizadas expuseram tão somente o lugar da atividade (em seus dois momentos: objetividade-subjetividade) no pensamento marxiano. Mas, é chegada a hora de adentrar o texto dos autores.

\section{O SEQUESTRO DA SUBJETIVIDADE: UMA IMPOSSIBILIDADE?}

Começo as considerações pela explicação oferecida por Faria e Meneghetti (2007, p. 50) no texto do livro supracitado. Segundo os autores, referenciando-se a um work paper de autoria de Faria (2003), o sequestro da subjetividade pode ser definido como:

O sequestro da subjetividade por parte da organização consiste no fato desta apropriar-se, planejadamente, através de programas na área de gestão de pessoas, e de forma sub-reptícia, furtiva, às ocultas, da concepção de realidade que integra o domínio das atividades psíquicas, emocionais e afetivas dos sujeitos individuais ou coletivos que a compõem (trabalhadores, empregados). Estas atividades formam a base da percepção e da representação que permite aos sujeitos interpretar o concreto pela via do pensamento e tomar atitudes (agir). O sequestro da percepção e da elaboração subjetiva priva os sujeitos de sua liberdade de se apropriar da realidade e de elaborar, organizar e sistematizar seu próprio saber, ficando à mercê dos saberes e valores produzidos e alimentados pela organização sequestradora (FARIA, 2003b apud FARIA; 
MENEGHETTI, 2007, p. 50) (Grifos da autora, para destacar a análise).

Em resumo, o sequestro da subjetividade é a apropriação da subjetividade do trabalhador por uma organização e se retornarmos a introdução do texto dos autores concluímos que essa apropriação foi propiciada pelo toyotismo e pela disseminação de certa ideologia. Diante disso, é preciso discutir primeiro a questão do sequestro enquanto uma apropriação feita por uma organização e oportunizada pelo toyotismo. Meu argumento é que não há alteração significativa no modo de apropriação particular capitalista que justifique a necessidade de chamar essa apropriação de sequestro. Após, adentrarei na discussão sobre o que é apropriado que, nas palavras de Faria (2003), é a concepção de realidade; quanto a isso, argumentarei que a subjetividade é simultaneamente produzida e apropriada, sendo consumida ao mesmo tempo em que é produzida, e produzida com conteúdo específico para ser consumida em um processo de apropriação também específico, de modo que não há nada externo que possa ser sequestrado e introduzido no processo de valorização.

Ademais, e para começar pelo fim da citação, pois trata de uma consideração breve, os autores explicam: "O sequestro da percepção e da elaboração subjetiva priva os sujeitos de sua liberdade de se apropriar da realidade e de elaborar, organizar e sistematizar seu próprio saber, ficando à mercê dos saberes e valores produzidos e alimentados pela organização sequestradora" (FARIA, 2003b). A compreensão do que para Marx é a sociedade, inviabiliza tal colocação, afinal, nem mesmo Robison Crusoé, como diria Marx, esteve livre dos saberes e dos valores produzidos e alimentados pelas relações sociais.

\subsection{A FORÇA DE TRABALHO E SUA APROPRIAÇÃO}

Como vimos, a apropriação é uma categoria universal. Não há relação humana, seja ela entre humanos ou entre humanos e a natureza, sem apropriação. Porém, essa apropriação manifesta-se de formas particulares e, sob o sociometabolismo do capital, a apropriação manifesta-se na forma de apropriação privada.

Os seres humanos possuem, enquanto elemento essencial, capacidade de trabalho. Desprovidos das possibilidades objetivas de se apropriarem dos meios necessários à produção, ou seja, "livres dos meios de produção", a única coisa que resta a esses humanos (que também estão livres de um senhor feudal ou escravocrata) é colocar a capacidade de trabalho à disposição da apropriação privada de quem possa usá-la no processo de produção de valores. Estabeleceu-se assim as condições para o desenvolvimento da relação de compra 
e venda da força de trabalho. A capacidade de trabalho, por meio da propriedade privada, é transmutada em força de trabalho, em uma mercadoria - com valor e valor de uso. Assim, a apropriação da força de trabalho manifesta-se como ocorre com qualquer outra mercadoria no sistema de capital. Nos termos assim postos, já é possível afirmar que a apropriação não pode ser uma relação de apropriação de uma força de trabalho por uma Organização.

$\mathrm{Na}$ imediaticidade do fenômeno, segundo o aparato jurídico, é possível dizer que uma Pessoa Jurídica - organização X, Y, Z - apropriou-se de uma Pessoa Física, porém, não é essa a essência da relação. O pesquisador necessita apontar para o fato de que essa apropriação trata apenas de uma forma de manifestação das relações sociais de produção na esfera jurídica. Esfera que, embora tenha sua lógica própria, guarda reciprocidade dialética com a esfera da produção, cuja determinância é da última. Mas é possível alegar que Organização, no conceito dos autores aqui trabalhados, não foi considerada em seu aspecto jurídico, mas como entidade social, como relações sociais despidas de toda e qualquer determinação, tornando-se um ente uno e indeterminado cujas vontades impõem-se sem explicações. Essa abstração arbitrária do real denuncia de forma mais veemente a necessidade de andar rumo à essencialidade das relações de troca subsumidas ao processo de valorização do valor, afinal, é justamente, segundo os próprios autores, a disseminação de uma ideologia capitalista que permitiria o sequestro da subjetividade. Quando um conceito que se propõe veículo para desvelar as ideologias está condicionado pela existência de uma categoria reificada, ele apenas reforça o que procura negar. Em suma, demonstrar que a apropriação das qualidades da força de trabalho é realizada por um grupo social específico - os capitalistas - (e não por organizações enquanto entidades sociais conforme afirmam os autores) é um avançar necessário ao desvelamento das ideologias.

Superar essa manifestação fenomênica de que uma entidade chamada Organização, seja ela produtiva ou não, apropria-se de algo - seja a subjetividade ou não - permite demonstrar, pelo menos, que: i) para a apropriação das qualidades de uma mercadoria como a força de trabalho não é imprescindível o estabelecimento de um contrato formal, tanto é verdade que dia após dia presenciamos alterações na esfera do direito do trabalho que corroem um conjunto de leis que representam conquistas da classe trabalhadora e que visavam diminuir um pouco as mazelas produzidas pela forma de sociabilidade do capital; ii) a categoria "Organização" tem caráter ideológico, pois se apresenta como um elemento que universaliza interesses particulares; afinal, essa entificação permite dizer algo como: o que o Estado é para a Classe Burguesa, a Organização é para os grupos particulares de Capitalistas.

Retornando ao processo de apropriação. Se a compra da força de trabalho é a 
condição necessária para os capitalistas privados disporem do valor de uso do elemento subjetivo do trabalho, não é a condição suficiente para que se extraia a máxima utilidade dessa força comprada. Nesse ponto, há consenso e, diga-se de passagem, desde Marx. O comprador da mercadoria necessita, para apropriar-se objetivamente do comprado, controlar o uso da mercadoria, afinal, o que é comprado é trabalho em potência: é a força subjetiva do trabalho que está objetivada em uma trabalhadora enquanto capacidade (capacidades físicas e espirituais, para usar terminologias de Marx). Realizar essa força subjetiva, objetivá-la, fixála em uma objetividade (de natureza material ou não) é o que necessita o comprador da força de trabalho para dela apropriar-se efetivamente. Como vimos, essa objetivação da subjetividade da trabalhadora está numa relação estranhada, de modo que a realização do processo não é autônoma, mas heterônoma. Desdobra-se assim a necessidade de um tipo específico de controle do processo de trabalho. Marx já chamava atenção da necessidade do controle n'O Capital, e, mais especificamente, do controle da trabalhadora no processo de trabalho subsumido às necessidades do processo de valorização. Somente com a ausência da categoria estranhamento poder-se-ia concluir que esse controle é um paradoxo.

Faria, em texto solo (2017, p. 70 ), tem acordo sobre a inexistência desse paradoxo embora não utilize a categoria estranhamento. $\mathrm{O}$ autor menciona que não há paradoxo no fato do Capital investir no "controle e no sequestro da subjetividade [do] que já lhe pertence", primeiro, porque o capital "não detém o controle imediato e total sobre a força de trabalho comprada"- mas não recorre a categoria estranhamento para explicar essa não imediaticidade, deixando subentender que se trata de uma falha do processo de aquisição da mercadoria que pode ser sanada pelos programas de gestão de pessoas que evoluíram conforme desenvolveram-se as abordagens científicas burguesas sobre o processo de trabalho, sendo o "toyotismo é a [como uma] forma contemporânea da racionalização do trabalho" (FARIA, 2017, p. 71, grifo da autora). Segundo, porque o Capital pretende "ter acesso a mais do que a força de trabalho adquirida por um equivalente de valor em um tempo de trabalho disponível contratado: pretende ter comando (e o controle) sobre a vida plena do trabalhador, apropriarse ideologicamente também de seu tempo livre, tornar-se a única referência existencial, detendo o monopólio de sua sedução" (FARIA, 2017, p. 70).

Para discutir com essas explicações do autor, preciso recorrer ao entendimento sobre a jornada de trabalho, a porosidade no processo de trabalho e a intensidade do trabalho. Não adentrarei na discussão sobre ideologia, mas deixo a questão: após a colocação sobre a categoria apropriação e sua manifestação particular, a apropriação privada, o que seria "apropriar-se ideologicamente"? 
Cabe lembrar aqui, antes de seguir, que: i) o valor de qualquer mercadoria é o tempo médio de trabalho socialmente necessário para a produção da mesma; ii) o que coloca em movimento a transferência de valores para a produção de novos valores ao mesmo tempo em que produz e cria valor é o trabalho vivo, porém esse é apenas um aspecto do duplo caráter do trabalho e da mercadoria; iii) há uma relação entre a transferência, a produção e a criação de valores e o tempo e a intensidade em que a força de trabalho é usada. Grosso modo, pensar sobre essa relação de uso da força de trabalho envolve considerar pelo menos esses elementos mencionados acima.

Antes de reiniciar o diálogo com Faria discutindo sua primeira explicação agora iluminada com as questões da porosidade no trabalho e intensidade do trabalho, acredito ser importante elucidar o que é o trabalho concreto em Marx. Marx ([1863] 2013 p. 124) ao explicar o duplo caráter da mercadoria (valor de uso e valor) enquanto resultado do duplo caráter do trabalho afirma:

Todo o trabalho é, por um lado, dispêndio de força humana de trabalho em sentido fisiológico, e graças a essa sua propriedade de trabalho humano igual ou abstrato ele gera o valor das mercadorias. Por outro lado, todo trabalho é dispêndio de força humana de trabalho numa forma específica, determinada à realização de um fim, e, nessa qualidade de trabalho concreto e útil, ele produz valores de uso.

Antes, Marx ainda esclarece os desdobramentos da variação da força produtiva na grandeza de valor. Para o autor:

Uma quantidade maior de trabalho, constitui, por si mesma, uma maior riqueza material, dois casacos em vez de um. Com dois casacos podem-se vestir duas pessoas; com um casaco, somente uma etc. No entanto, ao aumento da massa de riqueza material pode corresponder uma queda simultânea de sua grandeza de valor. Esse movimento antitético resulta do duplo caráter do trabalho. [...] A mesma variação da força produtiva, que aumenta a fertilidade do trabalho e, com isso, a massa dos valores de uso por ele produzida, diminui a grandeza de valor dessa massa total aumentada ao reduzir a quantidade de tempo de trabalho necessário à sua produção. E vice-versa (MARX, [1863] 2013, p. 123-124).

Realizado essas elucidações, retorno o diálogo com as proposituras de Faria. 


\subsubsection{Apropriação da força de trabalho, porosidade do processo de trabalho e intensidade do trabalho}

Faria afirma que o Capital "não detém o controle imediato e total sobre a força de trabalho comprada" $(2017,70)$. O preciso seria dizer: a compra da força de trabalho não garante ao capitalista que a trabalhadora objetive no processo de produção toda a sua energia (objetiva e subjetiva) de modo que o processo de objetivação precisa ser controlado. $\mathrm{O}$ controle - manifesto em distintos mecanismos - do capitalista sobre a trabalhadora é o elemento que medeia a garantia da objetivação das capacidades físicas e espirituais (subjetividade) da trabalhadora para diminuir ao máximo a porosidade no processo de trabalho.

Marx, n'O Capital, apresenta a metáfora da porosidade para demonstrar que no processo de trabalho há espaços temporais em que o uso da força de trabalho não está sendo realizado e que cabe ao capitalista desenvolver meios para eliminar essas porosidades aumentando assim o uso da força de trabalho dentro de um determinado tempo. Proceder dessa forma eleva a intensidade do trabalho.

Dal Rosso (2008, p. 20-21) menciona:

Qualquer trabalho - autônomo ou heterônomo, assalariado ou cooperativo, escravo ou servil, camponês, operário ou intelectual - é realizado segundo determinado grau de intensidade. Ela é condição intrínseca a todo trabalho concreto e está presente em todo tipo de trabalho executado, em maior ou menor grau. [...] A intensidade tem a ver com a maneira como é realizado o ato de trabalhar. [...] Ela se refere ao grau de dispêndio de energias realizado pelos trabalhadores na atividade concreta. A compreensão da noção de intensidade supõe ainda que a atenção esteja concentrada sobre a pessoa do trabalhador, sobre o coletivo dos trabalhadores e não sobre outros componentes do processo de trabalho que têm capacidades de alterar os resultados, tais como as condições tecnológicas. [...] A intensidade tem a ver tãosomente com o sujeito do trabalho, com o trabalhador individualizado ou com o coletivo dos trabalhadores.

Considerando, então, a necessidade da eliminação da porosidade do trabalho - o que é o mesmo que dizer: intensificação do trabalho - percebemos que não é, como parece ser na imediaticidade, que o toyotismo propiciou o "sequestro da subjetividade do trabalhador", o 
que temos é que: a necessidade de utilizar a força de trabalho no processo de produção em um novo patamar de valorização do valor, cujas bases materiais são tecnologicamente distintas das anteriores, demandou o desenvolvimento científico do modelo de organização do processo de trabalho denominado toyotismo. Utilizado, portanto, como um instrumento para a intensificação do trabalho, em busca do máximo consumo da força de trabalho, para a máxima objetivação das capacidades físicas e espirituais (subjetividade) da trabalhadora.

Apropriar-se privadamente da capacidade de trabalho das trabalhadoras é uma necessidade inexorável da forma societal capitalista. Acontece que as mudanças nas condições tecnológicas introduzidas pela ciência no processo produtivo surgem aos olhos dos pesquisadores de forma mais imediata fazendo parecer que delas resultam um novo fenômeno: o sequestro da subjetividade, quando, de fato, o que ocorreu foi uma descontinuidade na continuidade do processo de apropriação da força de trabalho. Algumas técnicas de gestão são substituídas por outras (descontinuidades) para que o processo de apropriação privada da força subjetiva do trabalho continue seu curso com a máxima intensidade, ou seja, para as capacidades de trabalho adquiridas no processo de troca sejam consumidas durante todo o tempo em que a trabalhadora se encontra no processo de trabalho. E ainda vale destacar que esse processo de trabalho não necessariamente, no atual estágio de desenvolvimento das forças produtivas, está limitado pela jornada legal de trabalho ou pelos limites geográficos da fábrica.

\subsubsection{Força de trabalho adquirida e jornada de trabalho}

Faria (2017, p. 70) menciona que o capital:

\section{[...] pretende ter acesso a mais do que a força de trabalho adquirida por um equivalente de valor em um tempo de trabalho}

disponível contratado: pretende ter comando (e o controle) sobre a vida plena do trabalhador, apropriar-se ideologicamente também de seu tempo livre, tornar-se a única referência existencial, detendo o monopólio de sua sedução. (Grifos da autora, para destacar a análise)

Pois bem, o capital não "pretende" ter acesso a mais do que a força de trabalho adquirida por um equivalente de valor em um tempo de trabalho disponível contratado. Primeiro, porque o Capital é uma forma de relação societal, personificada numa relação entre duas grandes classes, a capitalista (aquela que investe dinheiro na forma de capital) e a trabalhadora (aquela que para manter-se e reproduzir-se só tem como opção vender sua força 
de trabalho ao outrem - independente do formato jurídico contratual dessa troca). A existência dessa relação entre ambas as classes se constitui antagonicamente no processo de valorização de valores, que, por sua vez, não existe sem a produção de mais valor, sem a apropriação de mais-trabalho, ou seja, acessar mais do que o valor equivalente ao valor da força de trabalho é condição sine qua non dessa relação societal. Em resumo, não se trata de pretensão, mas de necessidade.

Bem, compreendo que Faria está ciente disso, e que o que ele pode estar querendo dizer é: i) o capitalista deseja, ao fazer uso da força de trabalho adquirida, acessar mais do que as qualidades técnicas da força de trabalho; ou, e mais provável, ii) que o capitalista deseja fazer uso da força de trabalho para além da jornada de trabalho.

Quanto à primeira afirmação, recorro a uma citação de Dal Rosso (2008, p. 21) para demonstrar a inviabilidade da força de trabalho ser usada desprovida da completude da trabalhadora.

Uma atividade concreta demanda em medida variável o concurso de todas as capacidades do trabalhador, ainda que a atividade faça uso mais focalizado, esta do esforço físico, aquela do cognitivo e uma terceira do afetivo. É o trabalhador em sua totalidade de pessoa humana que desenvolve a atividade, não apenas o trabalhador enquanto parte, força física, capacidade intelectual ou emocional. A intensidade é, portanto, mais que esforço físico, pois envolve todas as capacidades do trabalhador, sejam as de seu corpo, a acuidade de sua mente, a afetividade despendida ou os saberes adquiridos através do tempo ou transmitidos pelo processo de socialização. Além do envolvimento pessoal, o trabalhador faz uso de relações estabelecidas com outros sujeitos trabalhadores sem as quais o trabalho se tornaria inviável. São levadas em conta na análise da intensificação do trabalho as relações de cooperação com o coletivo dos trabalhadores a transmissão de conhecimentos entre si que permite um aprendizado mútuo - e as relações familiares, grupais e societais que acompanham o trabalhador em seu dia-a-dia e que se refletem dentro dos locais de trabalho, quer como problemas quer como potencialidades construtivas.

Como já dito, para que a apropriação da mercadoria se efetive conforme as necessidades de seu comprador é preciso colocá-la no processo de consumo de suas 
qualidades. Ou seja, a força de trabalho precisa ser consumida em nome do processo de produção, ou melhor, em nome do processo de valorização. A citação elucida a inviabilidade da compra de certas qualidades da capacidade de trabalho anular o envolvimento das demais qualidades humanas no processo de produção. Marx nos indica isso quando trata do trabalho concreto. Como é impossível a força de trabalho "ir ao trabalho" sem seu suporte, o humano, o capitalista ao fazer uso da mercadoria comprada acessa mais do que as qualidades técnicas necessárias ao processo de produção. Vale destacar, como fez Dal Rosso (2008), que esse acesso pode ou não garantir um dos desejos do capitalista: a intensificação do trabalho. Me parece que esse fenômeno está na raiz da problemática de Faria e Meneghetti (2007) cuja resposta encontrada foi o sequestro da subjetividade. Essa percepção tem base no próprio objetivo do estudo desenvolvido pelos autores "é investigado se as sutilezas presentes nas técnicas de produção e gestão toyotista [...] são capazes de promover o sequestro da subjetividade do trabalhador, levando-o a intensificar o ritmo do trabalho" (FARIA; MENEGHETTI, 2007, p. 46).

Quanto à segunda afirmação - que o capitalista deseja fazer uso da força de trabalho para além "do tempo de trabalho disponível contratado". Pois bem, Marx demonstra no capítulo 8 d'O Capital ([1863] 2013, p. 309) que:

Vemos que, abstraindo de limites extremamente elásticos, a natureza da própria troca de mercadorias não impõe barreira alguma à jornada de trabalho e, portanto, nenhuma limitação ao mais-trabalho. O capitalista faz valer seus direitos como comprador quanto tenta prolongar o máximo possível a jornada de trabalho e transformar, onde for possível, uma jornada de trabalho em duas. Por outro lado, a natureza específica da mercadoria vendida implica um limite de seu consumo pelo comprador, e o trabalhador faz valer seu direito como vendedor quando quer limitar a jornada de trabalho a uma duração normal determinada. Tem-se aqui, portanto, uma antinomia, um direito contra outro direito. Entre direitos iguais, quem decide é a força. E assim a regulamentação da jornada de trabalho se apresenta, na história da produção capitalista, como uma luta em torno dos limites da jornada de trabalho - uma luta entre o conjunto dos capitalistas, i.e., a classe capitalista, e o conjunto dos trabalhadores, i.e., a classe trabalhadora.

Portanto, Marx ([1863] 2013) demonstra que a jornada de trabalho é resultante da luta 
de classes. Um pouco antes dessa colocação, ele afirma que a jornada de trabalho é composta pelo tempo de trabalho necessário para a reprodução da mercadoria força de trabalho e pelo tempo de mais-trabalho; de modo que, no sociometabolismo do capital, a jornada de trabalho possui um limite mínimo: ela tem sempre que ser maior do que "a parte do dia que o trabalhador tem necessariamente de trabalhar para sua autoconservação" (MARX, [1863] 2013, p. 306). E possui também um limite máximo, sendo esse limite duplamente determinado.

Em primeiro lugar, pela limitação física da força de trabalho. Durante um dia natural de 24 horas, uma pessoa despende apenas uma determinada quantidade de força vital [...]. Além desses limites puramente físicos, há também limites morais que impedem o prolongamento da jornada de trabalho. O trabalhador precisa de tempo para satisfazer as necessidades intelectuais e sociais, cuja extensão e número são determinados pelo nível geral de cultura de uma dada época (MARX, [1863] 2013, p. 306).

Portanto, novamente, não é especificidade do modelo toyotista fazer uso da força de trabalho para além "do tempo de trabalho disponível contratado". O tempo contratado é uma questão limitada pelo aparato jurídico de uma determinada época, mas que na prática do processo produtivo não precisa ser respeitado em sua plenitude. De modo que, a jornada de trabalho pode ser expandida para além do tempo formalmente contratado até um ponto em que a tolerância cultural/moral da época permitir. Para além disso, intensifica-se a luta de classes em torno da jornada normal de trabalho, da qual o resultado pode ser o retorno ao que diz a lei ou a alteração da lei, seja para mais ou para menos, dependendo das forças de cada classe em luta ${ }^{7}$.

Nessa reflexão, coloquei em relevo a limitação legal posta à jornada de trabalho, mas há outra (i)limitação a essa jornada que a esfera jurídica ainda não regulariza em toda sua extensão: a tecnológica.

A existência do sociometabolismo do capital está sustentada nessa apropriação de toda a potencialidade do trabalho para a produção de mais valor, assim, uma extensão do tempo livre para além do mínimo de tempo necessário destinado a (re)produção da

\footnotetext{
${ }^{7}$ Marx destaca que quando o salário assume a forma salário por tempo, e quando o empregador não necessita contratar a trabalhadora por jornada, mas apenas nas horas que dele necessite de fato "A conexão entre o trabalho pago e o não pago é suprimida. o capitalista pode, agora, extrair do trabalhador uma determinada quantidade de mais-trabalho, sem conceder-lhe o tempo de trabalho necessário para sua autoconservação" (MARX, [1863] 2013, p. 616). Presenciamos a intensificação disso na alteração da CLT com o Trabalho Intermitente.
} 
mercadoria força de trabalho nada mais é do que um interesse imediato da classe trabalhadora que foi alcançado por meio de muitas lutas sindicais em momentos históricos específicos. E, esse tempo livre não tem como ser vivido sem estar permeado pelas relações capitalistas, conforme já discutido sobre a relação entre o desenvolvimento da individualidade e a sociedade. Ademais, o consumo da força de trabalho é realizado no processo de trabalho, processo que pode, inclusive, ser descontínuo durante o dia natural de 24 horas. O limite espacial e temporal dado por determinada forma tecnológica ao processo de produção condicionou nossa forma moral de compreender a jornada de trabalho, alterações na forma tecnológica estendem aqueles limites (FRANCO; FERRAZ, 2019).

Ainda, quanto à questão de tempo de trabalho disponível contratado, esse é um ponto que não pode estar limitado pela leitura do aparato jurídico e necessita da compreensão da categoria mais valor absoluto. A criação de valor ou o mais valor efetua-se no processo de trabalho e, se o processo de trabalho pode ser efetuado fora da jornada legal de trabalho, isso não altera em nada o processo de valorização. Em resumo: é da essência do sociometabolismo do capital fazer o uso da mercadoria que ele comprou ao máximo. E não uma essencialidade posta pelo modelo toyotista. Marx ([1863] 2013, p. 480) já havia observado que: "Daí este notável fenômeno na história da indústria moderna, a saber, de que a maquinaria joga por terra todas as barreiras morais e naturais da jornada de trabalho". Se na atualidade, determinadas qualidades da força de trabalho podem ser consumidas para além da jornada legal de trabalho e para além dos "muros da fábrica" estendendo assim a jornada de trabalho sem a alteração legal da mesma, isso não significa uma alteração na relação de apropriação capitalista, apenas que nessa luta entre as classes segue sendo uma necessidade a trabalhadora "vender a totalidade de seu tempo ativo de vida, até mesmo sua própria capacidade de trabalho, pelo preço dos meios de subsistência que lhe são habituais" (MARX, [1863] 2013, p. 343). Coisa que vêm fazendo há mais de 400 anos $^{8}$.

Porém, Faria e Meneghetti (2007) argumentariam que essa coação é de natureza distinta, pois tratar-se-ia de um poder condicionado. Sendo esse poder, uma forma de sequestro da subjetividade. E retorno ao conceito central discutido aqui. Após as reflexões apontadas e ainda sem considerar o objeto a ser "sequestrado", destaco que não há alterações qualitativas na forma de apropriação - ela segue sendo uma apropriação privada - que justifique a necessidade de nomeá-la sequestro. Não havendo essa alteração qualitativa na forma, seria a qualidade do objeto apropriado capaz de demandar a alteração categorial do fenômeno? Vejamos.

${ }^{8}$ Não entrarei no impacto disso para o mais valor absoluto. Ver Francisco de Oliveira (2008). 


\subsection{SEQUESTRAR O QUÊ?}

Seguindo o diálogo com Faria, ele menciona:

O controle e o sequestro da subjetividade, portanto, é uma estratégia

do Capital enquanto forma de apropriação da consciência crítica do trabalhador, apropriação esta que não se reduz apenas ao tempo total disponível de trabalho, que não está contida apenas no espaço físico do trabalho, mas que invade a vida mesma do trabalhador em seu tempo livre, em seu espaço particular (FARIA, 2013, p.70)

Creio não ser necessário resgatar a discussão sobre o "tempo total disponível de trabalho", tampouco sobre a possibilidade do processo de trabalho estar para além do "espaço físico" delimitado pelos muros das unidades produtivas. Vamos ao ponto crucial da discordância: "apropriação e controle da consciência crítica do trabalhador". Ou, como no conceito do texto de 2003, apropriação da concepção de realidade que integra o domínio das atividades psíquicas, emocionais e afetivas dos sujeitos individuais ou coletivos que a compõem (trabalhadoras, empregadas).

A primeira colocação que necessita ser realizada é que a trabalhadora não possui uma consciência crítica a priori. A trabalhadora, ou melhor, o ser humano possui consciência imediata da condição objetiva em que vive. E essa consciência é produzida nas relações objetivas de vida. É a subjetivação das relações objetivas estabelecidas pelos indivíduos durante sua existência e, por assim ser, não é meramente um processo racional, mas também uma operação que envolve afetividades (FERRAZ, et. al., 2017). Assim a consciência não "é uma relação do sujeito consigo mesmo" (FARIA; MENEGHETTI, 2007, p. 47), porque a própria individualidade do sujeito é uma individuação social. Destaco aqui que é aquela concepção de consciência que permite a Faria acreditar que há algo a priori que é colocado numa relação social de apropriação. A consciência é a consciência de uma época, ainda que seja um ato de subjetivação individuado e de uma objetividade social particular.

As discussões de Mészáros (2008) sobre consciência contingente e necessária de classe e as reflexões de Lukács (2010) sobre o processo de individuação permitem colocar que a consciência pode ser uma subjetivação parcial das condições objetivas ou uma subjetivação totalizada, onde a última não significa totalizante, mas sim uma interiorização mais completa das contradições existentes nas relações sociais objetivas. Essa última poderia ser análoga ao que os autores chamam de consciência crítica. Vale destacar que ter uma 
consciência imediata, não é afirmar a incapacidade cognitiva do indivíduo, mas ressaltar que o lugar que ele ocupa em decorrência da divisão social e técnica do trabalho, coloca a ele, de forma imediata, as possibilidades e necessidades de apreender o real em seu aspecto mais aparente, tão somente. Assim, desenvolver essa consciência crítica demanda que o indivíduo tenha, ao longo da vida, condições objetivas em que o conteúdo da apreensão imediata das relações sociais seja tensionado, para que sua consciência imediata se desenvolva rumo a uma consciência totalizada ou, em outras palavras, a uma consciência de classe, que só é de classe, porque as relações concretas assim são.

Iasi (2006) aponta que tais tensionamentos podem advir das experiências de outros e das frustrações práticas próprias de cada indivíduo. $O$ que o autor destaca é que o rompimento com a consciência imediata necessita de um questionar o arcabouço da consciência hegemônica da época - que interiorizamos nas relações sociais vivenciadas, relações que são estabelecidas entre sujeitos mutuamente indiferentes - produzido pelas condições objetivas dessas vivências. Mas, não basta romper com a consciência imediata para a constituição da consciência crítica, pois a contínua constituição da consciência crítica demanda o estabelecimento de novas e distintas relações sociais imediatas.

Agora, pergunto: o capitalista, ao "ir ao mercado" comprar força de trabalho, encontra apenas a sua disposição uma força de trabalho que possui tal consciência crítica? (Se assim fosse, saibam que não seriam os programas na área de gestão de pessoas o suficiente para apropriar-se dessa consciência crítica). Mas, não é o que ocorre. O capitalista tem a seu dispor uma mercadoria que possui uma consciência social parcializada, onde as contradições aparecem como obstáculos individuais a serem superados, posto o estabelecimento de relações sociais de dependência entre indivíduos mutuamente indiferentes. É essa a consciência que o capitalista encontra compondo a mercadoria que ele compra. De modo que, os programas na área de gestão não se apropriam da consciência crítica, mas sim mobilizam de forma condicionante uma determinada consciência parcializada para que ela seja objetivada no processo de produção segundo as demandas do capitalista privado, esteja o processo de trabalho numa linha de montagem dentro da fábrica, na palma da mão em um aeroporto qualquer ou ainda, numa planilha preenchida pelo sujeito em frente ao mar numa suposta e desejadas férias. Ou seja, os programas de RH não medeiam a apropriação de uma subjetividade específica do sujeito na forma de sequestro. Os programas de RH tão somente indicam para as trabalhadoras os parâmetros em que o consumo da força de trabalho (física e espiritual) deve ser efetivado para que as trabalhadoras sigam se reproduzindo como trabalhadoras. 
Nesse sentido, o conceito de sequestro da subjetividade de Faria em 2003 a estava mais próximo de uma apreensão do real do que o conceito que ele apresenta em seu livro de 2013, pois no texto de 2003 o autor afirmou tratar-se da apropriação da "concepção de realidade", não qualificando-a como consciência crítica (FARIA, 2014). Mas o problema está no desdobramento do que ele considera concepção da realidade. Faria afirma que o sequestro é da percepção e da elaboração subjetiva do sujeito. E esse sequestro "priva os sujeitos de sua liberdade de se apropriar da realidade e de elaborar, organizar e sistematizar seu próprio saber, ficando à mercê dos saberes e valores produzidos e alimentados pela organização sequestradora" (FARIA, 2003 apud FARIA; MENEGHETTI, 2007, p. 50-51).

Primeiro, não é possível privar um sujeito de "apropriar-se da realidade", ou em outros termos, interiorizar a externalidade, subjetivar a objetividade, afinal, essa é uma característica humana. Nenhum capitalista deseja que a trabalhadora deixe de "apropriar-se da realidade". Ainda que Ford tenha afirmado que desejava que a sua trabalhadora deixasse a cabeça no vestiário, o que ele quis dizer é que a trabalhadora não deveria pensar em coisas alheias ao trabalho no processo de trabalho, jamais que a trabalhadora não efetuasse a apropriação da objetividade vivida, sua realidade imediata. Sem essa apropriação, o próprio processo de trabalho estaria impossibilitado.

Bem, mas isso não foi o que Faria colocou, uma vez que ele afirma que o sequestro priva os sujeitos da liberdade de se apropriar da realidade e sistematizar seu próprio saber. Agora, precisamos entender que liberdade é essa. Primeiro, somente compreendendo a consciência como uma relação do sujeito consigo mesmo é que tal condicionamento não existiria e a liberdade seria algo pleno. Já argumentei que a subjetividade não é uma relação do sujeito consigo mesmo, então, passo ao segundo traço que caracteriza o entendimento de liberdade apresentado pelos autores. Observo na leitura de Faria e Meneghetti (2007) sobre a constituição da subjetividade humana traços da concepção de Spinoza, para o qual indivíduos, vivendo em sociedade têm o direito de liberdade em relação aos pensamentos. Essa concepção, presente numa escola do conhecimento conhecida como contratualismo, justifica teoricamente o liberalismo burguês, afirmando o pleno poder dos governantes estatais para a organização da vida em sociedade desde que o direito da liberdade de pensamento não seja cerceado. Há traços desse argumento na explanação de Faria e Meneghetti (2007), pois em épocas de Sequestro da Subjetividade a entidade Organização está sendo criticada por privar o indivíduo da liberdade de se apropriar da realidade, não sendo isso, está autorizada a organizar a vida em sociedade. E quanto aos demais cerceamentos? Explorações? Opressões? 
Não entrarei em possíveis respostas a essas perguntas, sumariamente destaco apenas que, até o momento, o desenvolvimento da ciência não alcançou a potencialidade de a "organização" e/ou o Estado privar a liberdade de pensamento (embora a neurociência já tenha algumas pistas que podem nos levar a algo parecido, abrindo a possibilidade de alteração na própria natureza do ser humano), seja pelo já discutido sobre a categoria organização seja porque a consciência é - ainda - condição humana e um ato social, sua natureza é ontoprática, logo, não há tal liberdade do sujeito no sentido pleno. Possuindo condições biológicas necessárias, toda unidade da espécie humana irá apropriar-se da realidade imediata em que vive e formulará seu saber sobre suas condições objetivas de vida e, como as condições objetivas de vida são sínteses de múltiplos determinantes, a experiência de cada unidade da espécie será única, mas ser única não significa, de fato, ser distinta em seus traços da generidade.

Ainda, sobre a crença na liberdade individual tão cara aos liberais burgueses presente nas considerações de Faria e Meneghetti (2007) vale ressaltar a crítica que eles fazem ao capitalismo contemporâneo que produziu o que chamam de subjetividade fragmentada. Para os autores, o sequestro da subjetividade é possível porque "a subjetividade do trabalhador tornou-se fragmentada". E o que é essa subjetividade fragmentada? É uma "doação forçada" que o sujeito faz de sua subjetividade para o coletivo. Retomando as considerações sobre o par objetividade-subjetividade e a relação sociedade-indivíduo, destaco que se não houver a exteriorização da subjetividade não há relação social. A exteriorização da subjetividade é condição sine qua non da própria humanidade. Percebe-se na reflexão que os autores fazem sobre a subjetividade fragmentada a persistência da dualidade indivíduo-sociedade. Onde esse indivíduo é agora um sujeito psíquico dotado de um "desejo total" que é castrado por ser obrigado a viver em sociedade, obrigado a "abrir mão de parte de sua autonomia" (FARIA e MENEGHETTI, 2007, p. 48). Porém, esse fenômeno observado pelos autores é justamente momento de um ato de realização do indivíduo racionalmente egoísta e sua autonomia é justamente estar livre para realizar-se na relação de troca com outros para efetivação de seus interesses, a efetivação do interesse de um indivíduo somente se realiza quando este coloca-se como meio para a realização do interesse de outro numa relação de reciprocidade. Na sociabilidade onde prepondera o valor de troca das mercadorias, "o interesse universal é justamente a universalidade dos interesses egoístas” (MARX, [1857/1858] 2011, p. 188).

A adoção de conceitos construídos com epistemologias distintas e que em comum têm a ontologia idealista resulta no abandono do indivíduo enquanto uma produção histórica na generidade humana. Abandono que tira o foco de que esses "desejos totais" são produtos de 
uma sociabilidade antagônica e que a não satisfação dos mesmos decorre, em geral, não por viver em sociedade, mas por viver em uma sociedade em que a trabalhadora deve satisfazer apenas os "desejos" necessários à reprodução de sua força de trabalho, ou como diria Marx ([1844], 2010), porque ainda vivemos no reino das necessidades, onde não há o livre desenvolvimento do indivíduo como desenvolvimento da humanidade.

\section{NÃO HÁ SEQUESTRO PORQUE NÃO HÁ LIBERDADE NO CAPITAL}

A adoção de conceitos que perpetua a dicotomia indivíduo-sociedade e legitimam o ideário burguês é um obstáculo para qualquer pesquisador à apropriação da essência do real concreto pelo pensamento, pois tais conceitos carregam em si as contradições que ocultam. Observo isso no pensamento de Faria e Meneghetti (2007), sobretudo, quando advogam uma essência natural para a subjetividade humana que, sendo livre, não se realiza em sua plenitude em função da necessidade de estabelecer relações sociais. Somente nesses termos é possível pensar em sequestro da subjetividade. E assim, mesmo sem declarar, os autores reforçam o ideário existencialista "o inferno são os outros". Brincadeiras à parte, o meu, são os boletos mensais.

São as relações sociais estabelecidas no cotidiano da existência as produtoras da subjetividade. Se, portanto, o desenvolvimento omnilateral da subjetividade humana está limitada, não é porque a subjetividade não se realiza ou porque ela está sequestrada, mas porque as relações sociais concretas são, em última instância, determinadas por relações sociais de troca de mercadorias. Enquanto vendedor de força de trabalho, minhas possibilidades de vida estão limitadas pelas necessidades da produção da capacidade de trabalho enquanto mercadoria. Reproduzir minha existência é, portanto, constantemente reproduzir um valor de troca, cujo valor de uso interessa ao investidor do dinheiro como capital. A liberdade que existe nas sociabilidades do capital são, portanto, não sermos propriedades de ninguém e estarmos livres da propriedade dos meios necessários à produção. Essa liberdade, por sua vez, nos aprisiona em uma forma de relação social que nos produz objetiva e subjetivamente, de modo que nos submeter ao "desejo" de um empregador qualquer é uma necessidade individual imediata e para que essa submissão seja superada, necessário se torna superar a subsunção real do trabalho ao capital.

A apropriação privada das capacidades de trabalho pela compra da força de trabalho é a base das relações sociometabólicas do capital. O capitalista pretende ter acesso a toda a potencialidade da força de trabalho. É importante não confundir o valor da força de trabalho e 
o valor de uso dessa força de trabalho, pois são expressões distintas do duplo caráter dessa mercadoria vendida. É preciso compreender, também, que o capital é uma relação social que tem como determinante sua valorização e essa ocorre não somente na esfera da produção direta, onde prepondera o trabalhador produtivo, mas na totalidade do processo de produção. Marx ([1857-1858] 2011) explica essa totalidade do processo demonstrando como produção, circulação, troca e consumo são distintos momentos de uma unidade. Unidade que necessita ser apreendida como processo de valorização (criação e realização do valor) e processo de trabalho. Unidade que necessita ser apreendida como produtora de mercadorias a serem consumidas e como produtora de seus consumidores.

Portanto, as relações sociais capitalistas não invadem nosso tempo de livre, elas determinam sua extensão como também as diversas formas possíveis de o consumir e, nossa escolha, em geral, é aquela que mais se adequa a necessidade de reprodução da nossa força de trabalho. Se, com o avanço tecnológico, parte do processo de trabalho pode ser feito "fora da fábrica", estamos tendo a extensão do nosso tempo livre encurtada, ainda que formalmente/legalmente a jornada de trabalho não tenha se alterado. Trata-se, portanto, do avanço tecnológico oportunizando o aumento do mais valor absoluto. Eis porque nunca é inoportuno recuperar a indagação de Tragtenberg (2004, p. 17): "o conhecimento a que e para quem serve?"

Ademais, como coloca Marx ([1859] 1996, p. 358-359):

Não basta que as condições de trabalho apareçam num pólo como capital e no outro pólo, pessoas que nada têm para vender a não ser sua força de trabalho. Não basta também forçarem-nas a se venderem voluntariamente. $\mathrm{Na}$ evolução da produção capitalista, desenvolve-se uma classe de trabalhadores que, por educação, tradição, costume, reconhece as exigências daquele modo de produção como leis naturais evidentes. A organização do processo capitalista de produção plenamente constituído quebra toda a resistência, a constante produção de uma superpopulação mantém a lei da oferta e da procura de trabalho e, portanto, o salário em trilhos adequados às necessidades de valorização do capital, e a muda coação das condições econômicas sela o domínio do capitalista sobre o trabalhador.

Atentamos para a sutileza: os diferentes modos de organização da produção produzem subjetividades que são compatíveis com suas necessidades. E os produz durante todo o tempo de vida, posto que a classe proprietária dos meios de produção material da vida é também a 
classe proprietária dos meios de produção espiritual "de modo que a ela estão submetidos aproximadamente ao mesmo tempo os pensamentos daqueles aos quais faltam os meios de produção espiritual. As ideias dominantes não são nada mais do que a expressão ideal das relações materiais dominantes [...]" (MARX, [1845-46], 2007, p. 47).

Por fim, um desdobramento problemático da apreensão do fenômeno como sequestro da subjetividade está na solução apresentada por eles para a libertação da trabalhadora:

A liberdade do sequestrado se dá (i) pela fuga ou pelo rompimento da relação de subordinação, de iniciativa do sujeito (individual ou coletivo), (ii) pela negociação entre os sequestrados e a associação coletiva representativa do sujeito (por exemplo, o sindicato), quando o sequestrado percebe que se encontra em cativeiro e consegue contatar um negociador institucional ou (iii) pelo sequestrador e uma instância de mediação (por exemplo, o Tribunal Regional do Trabalho) (FARIA; MENEGHETTI, 2007, p. 51).

Primeiro, considerando o conceito dos autores, se o sequestro da subjetividade é a privação da trabalhadora da liberdade de apropriar-se da realidade e sistematizar seus saberes; o sequestro teria fim no ato de perceber que se encontra "em cativeiro", logo, não se faz necessário nem fuga, nem negociação sindical nem mesmo interferência da justiça burguesa, ainda que seja denominado Justiça do Trabalho. Mas, considerando aquelas sugestões dos autores, destaco que tais medidas não libertam de fato a trabalhadora de sua condição de trabalhadora, no máximo são os estopins para o avanço da constituição de uma subjetividade menos parcializada, como demonstrou Iasi (2012).

A libertação da trabalhadora é a libertação da classe trabalhadora e, nesse caso, não se trata de fuga ou negociação, mas de superação, de alteração total das atuais relações metabólicas da sociedade; cujo "valor do resgate" não é o "preço da pactuação voluntária [...] da punição (demissão, desligamento [...]), da transgressão ou da extinção das regras que permitem à organização agir como sequestradora" (FARIA; MENEGHETTI, 2007, p. 51), mas a abolição da propriedade privada dos meios de produção, a superação da politicidade, a superação do trabalho abstrato. Em suma, a superação da auto-alienação do trabalho para a construção das condições concretas da realização da humanização da humanidade. Disso, não me restam dúvidas que Faria assinaria embaixo. 


\section{REFERÊNCIAS}

COSTA, M. H. A exteriorização da vida nos Manuscritos Econômico-Filosóficos de 1844.

Verinotio, Ano II, n. 4, 2006. Disponível em:

http://www.verinotio.org/sistema/index.php/verinotio/article/view/24. Acesso em: 13 abr. 2019.

BICALHO, R. A. Elementos para uma análise categorial da objetividade/subjetividade em O capital (1867): um aporte teórico para os Estudos Organizacionais Marxistas. Tese de Doutorado, Cepead, UFMG, 2014.

DAL ROSSO, S. Mais trabalho! A intensificação do labor na sociedade contemporânea. São Paulo: Boitempo, 2008.

FARIA, J.H. de. Economia política do poder. Curitiba: Juruá, 2004.

FARIA, J. H. de; MENEGHETTI, F. K. O Sequestro da Subjetividade. In: FARIA, J. H. Análise crítica das teorias e práticas organizacionais. São Paulo: Atlas, 2007, p. 45-67. FARIA, J. H. de. Poder, controle e gestão. Curitiba: Juruá, 2017.

FERRAZ, D. L. S.; MOURA-PAULA, M.; BIONDINI, B. K. F.; GUERRA, A. Ideologia, subjetividade e afetividade nas relações de trabalho: análise do filme 'Que horas ela volta?'.

Revista Brasileira de Estudos Organizacionais, v. 4, n. 1, p. 278-318, 2017.

FRANCO, D. S.; FERRAZ, D. L. S. Uberização do trabalho e acumulação capitalista. Cadernos EBAPE.BR (FGV), 2019 (no prelo).

IASI, M. As metamorfoses da consciência de classe. São Paulo: Boitempo, 2013.

LUKÁCS, G. Prolegômenos para uma ontologia do ser social Boitempo: São Paulo, 2010.

LUKÁCS, G. Para uma ontologia do ser social II. Boitempo: São Paulo, 2013

MARX, K. Para a crítica da economia política do capital. São Paulo: Nova Cultural, 1996.

MARX, K.; Sobre a questão judaica. São Paulo: Boitempo, 2010.

MARX, K.; Grundrisse: manuscritos econômicos 1857-1858. São Paulo: Boitempo; Rio de Janeiro: Edu UFRJ, 2011.

MARX, K. O Capital: Crítica da Economia Política: Livro I: O processo de Produção do Capital. São Paulo: Boitempo, 2013.

MARX, K. O Capital: Crítica da economia política: Livro II: O processo de Circulação do Capital. São Paulo: Boitempo, 2014.

MARX, K. O Capital: Crítica da economia política: Livro III: O processo Global da Produção Capitalista. São Paulo: Boitempo, 2017.

MARX, K.; ENGELS, F. A ideologia alemã. São Paulo: Boitempo, 2007. 
MÉSZÁROS, I. A Teoria da alienação em Marx. São Paulo: Boitempo, 2006.

MÉSZÁROS, I. Para Além do Capital. São Paulo: Boitempo, 2006.

MÉSZÁROS, I. Consciência de classe necessária e consciência de classe contingente. In:

MÉSZÁROS, I. Filosofia, ideologia e ciência Social. São paulo: Boitempo, 2008, p. 55-90.

OLIVEIRA, F. Crítica à razão dualista o ornitorrinco. São Paulo: Boitempo, 2008.

TRAGTENBERG, M. Sobre educação, política e sindicalismo. São Paulo: Editora da Unesp, 2004.

VAISMAN, E. Marx e Lukács e o problema da individualidade: algumas aproximações.

Perspectiva, v. 27, n. 2, p. 441-459, jul./dez. 2009. Disponível em:

http://www.perspectiva.ufsc.br. Acesso em: 22 mar 2019. 